\title{
La fertilisation phosphatée raisonnée de la culture du blé
}

\author{
C Morel 1, C Plenchette 1, JC Fardeau 2 \\ 1 INRA-Agronomie, 17, rue Sully BV 1540, 21034 Dijon Cedex; \\ 2 CEN Cadarache DPVE, 13108 St-Paul-lez-Durance, France
}

(Reçu le 21 février 1992; accepté le 12 juin 1992)

\begin{abstract}
Résumé - Les relations existant entre le rendement en grain de la culture de blé et le statut phosphaté du sol ont été établies puis analysées afin de proposer une stratégie de la fertilisation phosphatée $(P)$ sur blé. Les données culturales et analytiques sont issues des récentes synthèses réalisées sur 40 essais de longue durée conduits sur l'étude de la fertilisation phosphatée. Trois régimes d'apport de phosphore y sont étudiés : $P_{0}$, absence de tout apport; $P_{1}$, apport voisin de 1,5 fois les exportations par les cultures; $P_{2}$ égal à 2 fois $P_{1}$. Le statut phosphaté du sol a été estimé au moyen d'une part, des quantités de $P$ extrait par les méthodes chimiques Dyer (P-Dyer), Joret-Hébert $(P-J H)$ et Olsen (P-Olsen), et d'autre part par la quantité de phosphore isotopiquement échangeable en 1 min ( $\left.E_{\mathrm{Pie} 1}\right)$. Le comportement cultural du blé a été décrit par un indice de rendement (IR) exprimant le rendement en grain mesuré sur $P_{0}$ ou $P_{1}$ en pourcentage de celui obtenu dans $P_{2}$ considéré comme condition optimale d'alimentation en phosphore. Les valeurs de $I R$ sont corrélées avec le statut phosphaté du sol par les équations suivantes:
\end{abstract}

$I R=100-81,4 \times \exp [-0,031 \times(P-D y e r)](18$ essais $)$

$I R=100-70,2 \times \exp [-0,036 \times(\mathrm{P}-\mathrm{JH})](24$ essais $)$

$I R=100-36,4 \times \exp [-0,070 \times$ (P-Olsen) $]$ (22 essais)

$I R=100-37,8 \times \exp \left[-0,53 \times\left(E_{\mathrm{Pie} 1}\right)\right]$ (11 essais).

Les niveaux de phosphore ( $\mathrm{mg} \mathrm{P}_{2} \mathrm{O}_{5} \mathrm{kgg}^{-1}$ de sol) permettant l'obtention de $95 \%$ du rendement maximal en grain de la culture de blé et calculés au moyen des équations précédentes sont de 90 pour le P-Dyer, 73 pour P-JH, 28 pour POlsen et 8,7 pour $E_{\text {Pief }}$. L'analyse, culture par culture, des données issues des essais de fertilisation $P$ longue durée permet d'élaborer des conseils de fertilisation phosphatée évitant la surfertilisation sans réduire les rendements des cultures.

blé / phosphore / diagnostic de fertilité / niveau entretien / conseil de fumure

Summary - The management of phosphate fertilization in wheat crops. The analytical soil and wheat yield data obtained from many long-term field experiments on phosphate fertilization have been analyzed. There were three $P$ treatments: $P_{0}$, without $P$ fertilizer; $P_{1}$ about 1.5 times the annual $P$ output by crops; and $P_{2}$ which is $2 \times P_{1}$. Soil $P$ status was determined by chemical extraction, according to the methods of Dyer (P-Dyer), Joret-Hébert $(P$-JH) and Olsen ( $P$-Olsen) and also by means of an isotopic exchange procedure for determining the quantity of $\mathrm{PO}_{4}$-ions isotopically exchanged in $1 \mathrm{~min}\left(E_{P i e 1}\right)$. Wheat yields were transformed into a relative yield index (IR) defined as the ratio, expressed in percentage, of wheat yield observed in the $P_{0}$ or $P_{1}$ treatment to that measured in the $P_{2}$ treatment considered as optimal condition of $P$ nutrition to crops. IR values and soil $P$ status were correlated according to the following equations:

$\mathrm{IR}=100-81.4 \times \exp [-0.031 \times(P-D y e r)](18$ trials $) ;$

IR $=100-70.2 \times \exp [-0.036 \times(P-J H)](24$ trials $) ;$

IR $=100-36.4 \times \exp [-0.070 \times(P-O l s e n)](22$ trials $) ;$

$\mathrm{IR}=100-37.8 \times \exp \left[-0.53 \times\left(E_{\text {Pie } 1}\right)\right](11$ trials $)$.

The soil $P$ levels, expressed in $\mathrm{mg} \mathrm{P}_{2} \mathrm{O}_{5} \mathrm{~kg}^{-1}$ soil, the above $95 \%$ of maximum grain yield in wheat and calculated by means of equations were: 90 for P-Dyer, 73 for $P$-JH, 28 for $P$-Olsen and 8.7 for $E_{\text {Pier. }}$. This approach allowed permitting the obtainment of to make $P$ fertilizer recommendations for wheat crop to be made, preventing overfertilization without reducing crop yields. 


\section{INTRODUCTION}

Un des objectifs des agronomes en matière de fertilisation phosphatée est de fournir aux agriculteurs des conseils fiables et précis afin de placer les cultures dans une situation où leur nutrition phosphatée n'est pas le premier des facteurs limitant la production. En moyenne, une culture prélève $80 \%$ du phosphore qui lui est nécessaire à partir de la fraction biodisponible du phosphore du sol, et $20 \%$ à partir de la fumure annuelle apportée avant la culture (Morel, 1988). Même si ces proportions varient en fonction du niveau du statut $P$ du sol et de la quantité d'engrais apportée (Morel et Fardeau, 1989), le rôle des réserves assimilables du sol en phosphore est prépondérant en toute circonstance. $\mathrm{Ce}$ constat a conduit les agronomes à proposer de porter la réserve assimilable du sol à un niveau dit "d'entretien", niveau pour lequel un apport d'engrais phosphaté n'entraîne pas d'accroissement de rendement. Des expérimentations de plein champ, dont certaines existent désormais depuis plus de 20 ans, ont été mises en place afin de déterminer ce niveau.

Trois publications récentes (Boniface et Trocmé, 1988; Martinez et Delas, 1990; Castillon, 1991) contiennent l'ensemble des données analytiques et culturales obtenues dans une cinquantaine d'essais de longue durée menés sur la fertilisation $P$ et implantés en France. Elles portent principalement sur la comparaison, au cours du temps, des méthodes d'appréciation du statut phosphaté et des rendements des cultures en fonction du régime de fertilisation $P$. Mais les informations issues de cet ensemble de données ne permettent pas d'établir un diagnostic du statut qui permettrait de prévoir, au vu du résultat d'une analyse de terre, les situations pour lesquelles : 1) le phosphore est le premier facteur limitant de la production végétale, ce qui nécessite d'apporter une fumure phosphatée très supérieure aux exportations par les récoltes pour éliminer cette limitation; 2) la stricte restitution des exportations suffit à maintenir le statut $\mathrm{P}$ à un niveau optimal de nutrition correspondant à «l'entretien»; 3) un apport de phosphore inférieur aux exportations pour les récoltes peut être conseillé, sans entraîner une diminution des rendements des cultures.

L'échec des tentatives les plus récentes entreprises pour préciser ces différentes situations tant pour le phosphore (ITCF, 1988) que pour le potassium (Julien, 1989) a pour origine la varia- bilité des résultats culturaux dont une part importante est imputable at choix de la culture. En conséquence, une approche globable de la détermination du niveau d'entretien intégrant l'ensemble des sites expérimentaux et des cultures masque les spécificités de comportement propres à chaque culture. C'est pourquoi la démarche proposée consiste à tenter d'estimer le niveau d'entretien pour chaque culture.

Le blé, plante fréquemment présente dans les rotations rencontrées dans les zones de grande culture, est choisi comme première culture d'étude pour ce type d'approche.

\section{MATÉRIEL ET MÉTHODES}

\section{Les essais $P$ longue durée}

Pour établir des relations utilisables dans les conditions de la pratique agricole, l'Institut national de la recherche agronomique (INRA), des Instituts techniques et des producteurs d'engrais ont mis en place des réseaux d'expérimentation de plein champ destinés à fournir les informations indispensables à la conduite raisonnée de la fertilisation phosphatée des plantes de grandes cultures (céréales essentiellement). La majorité de ces essais de longue durée avaient un protocole unique. Le dispositif expérimental était du type bloc à 3 ou 4 répétitions pour 3 niveaux d'apport de phosphore :

- absence continue de tout apport $\left(P_{0}\right)$;

- compensation des exportations de phosphore par les cultures et des éventuelles pertes par lessivage ou rétrogradation $\left(P_{1}\right) ; P_{1}$ est généralement voisin de 1,5 fois les exportations;

- apport égal au double de $P_{1}\left(P_{2}\right)$ afin de placer la culture dans des conditions optimales d'alimentation en phosphore:

Tous les apports d'engrais phosphatés sont effectués à l'automne, avant labour, sous forme de superphosphäte. Les rotations culturales sont essentiellement à dominante céréalière.

Les principales caractéristiques (localisation, type de sol, niveau de $P_{1}$ et statut $P$ initial) des essais $P$ longue durée sont présentées dans le tableau I. Des informations complémentaires décrivant les caractéristiques physico-chimiques initiales ainsi que l'évolution du statut phosphaté au cours du temps ont été publiées antérieurement (Boniface et Trocmé, 1988; Martinez et Delas, 1990; Castillon, 1991).

\section{Les données culturales}

Les rendements culturaux ont été mesurés chaque année pour l'ensemble des cultures de la rotation. Les 
rendements en grain du blé retenus dans la recherche des relations entre le comportement cultural et le statut $P$ des sols sont ceux des années $X-1, X$ et $X+1$ où $X$ désigne l'année de prélèvement des échantillons de terre. Cette démarche est justifiée par le fait que, même si les variations interannuelles du statut $P$ d'un sol donné peuvent être importantes (Boniface et Trocmé, 1988), la part de cette variabilité imputable soit à une fumure annuelle, soit à une année d'exportation de $P$ par les cultures, ne dépasse pas 2 à $3 \%$ de la teneur en $P$ extrait (Barrow, 1980).

Dans un site expérimental donné, les variations interannuelles du rendement en grain du blé sont souvent supérieures à celles observées une année donnée entre les traitements $P_{0}$ et $P_{1}$ ou même $P_{0}$ et $P_{2}$. Le même constat est valable d'un site à un autre. Comme il est nécessaire de s'affranchir des variations interannuelles et intersites pour comparer les rendements en grain du blé, il est habituel de transformer les données culturales au moyen d'un indice de rendement (IR) (Nelson et Anderson, 1980; Fox et al, 1986; Boniface et Trocmé, 1988; Julien, 1989). Cette transformation consiste à rapporter les rendements observés sur les traitements $P_{0}$ ou $P_{1}$ à celui mesuré sur $P_{2}$, considéré comme condition optimale de nutrition phosphatée et utilisé comme rendement de référence. L'IR ainsi défini et exprimé en pourcentage permet la comparaison des résultats des différents couples essai $x$ année.

\section{Les données analytiques}

Des échantillons de terre ont été prélevés tous les 5 ans environ dans chaque parcelle élémentaire, séchés puis tamisés à $2 \mathrm{~mm}$. À la mise en place de chaque essai, l'appréciation du statut phosphaté a été réalisée en déterminant les quantités de phosphore extractible par les principales méthodes chimiques utilisées dans les laboratoires d'analyses de sol. Deux méthodes d'extraction ont ainsi été pratiquées : 1) la méthode Dyer (P-Dyer), acide citrique à $2 \%$, appliquée aux sols acides ou neutres dont la teneur en $\mathrm{CaCO}_{3}$ est inférieure à $2 \%$ (Boniface et Trocmé, 1988); 2) la méthode Joret et Hébert (P-JH), oxalate d'ammonium $0,2 \mathrm{~N}$, utilisée en France principalement en milieu calcaire.

Des travaux ont montré les limites de ces méthodes (Admont et al, 1986) et l'intérêt de la méthode Olsen mise au point initialement pour les sols calcaires puis étendue à des nombreux autres types de sols (Morel et Fardeau, 1987; Fardeau et al, 1988; Boniface et Trocmé, 1988). C'est pourquoi, dans les cas où les échantillons étaient encore disponibles, les déterminations Dyer et Joret-Hébert ont été complétées par celle de Olsen.

Pour quelques essais, une caractérisation plus détaillée du statut phosphaté a été obtenue par utilisation de la méthode des cinétiques d'échange isotopique des ions phosphate dans des systèmes sol-solution de sol en état stationnaire (Fardeau et al, 1991). Les modalités expérimentales ont été largement décrites (Fardeau, 1981; Fardeau et al, 1988; Tran et al, 1988; Sal- cedo et al, 1991). La quantité $\mathrm{E}_{\mathrm{Pie} 1}$ de phosphore isotopiquement échangeable en $1 \mathrm{~min}$, représentative de la quantité de phosphore du sol disponible pour la plante sans modification physico-chimique de la rhizosphère, est la seule variable déduite de ces expériences qui a été prise en compte dans cette étude. $E_{\mathrm{Pie} 1}$ est calculé par la relation suivante:

$$
\mathrm{E}_{\mathrm{Pie} 1}=10 \times C p /(\mathrm{H} / R)
$$

où $\Pi / R, C p$ et 10 désignent respectivement la fraction de radioactivité restant en solution après une minute d'échange isotopique, $C p$ la concentration de la solution de sol en ions phosphate et le rapport solution de sol:sol.

\section{Analyses statistiques}

Les relations entre la valeur de l'indice de rendement et les données analytiques ont été décrites par l'équation : IR $=100-b \times \exp (-c \times$ Pass $)$, où Pass désigne la donnée analytique caractérisant le statut $P$ du sol. La détermination des paramètres $b$ et $c$ a été effectuée par une analyse statistique de régression non linéaire en utilisant la procédure NLIN du logiciel SAS/ STA (SAS Institute, 1987).

\section{RÉSULTATS ET DISCUSSION}

Quarante essais implantés sur 33 sites ont pu être utilisés sur la base des critères choisis. Les rendements en grain du blé et les données analytiques des différents essais ont été regroupés dans le tableau II. Ces valeurs ont été collectées dans différentes publications portant sur l'analyse des résultats de ces essais (Boniface et Trocmé, 1988; Martinez et Delas, 1990; Castillon, 1991; Fardeau, 1991; Morel et Plenchette, 1991). Ces données correspondent à :

- 46 années de référence sur les données analytiques, puisque certains essais ont été analysés sur plusieurs périodes successives : essais $13,14,15,51$;

- 55 années de référence sur les données culturales puisque les rendements en grain du blé ont été mesurés 2 fois sur la période des 3 années $X-1, X, X+1$ pour les essais $1,9,21,22$, $23,49,78,79,80$.

\section{Les rendements en grain du blé}

La valeur moyenne du rendement en grain du blé dépend largement du site et de l'année de culture, puisqu'il est compris entre 28,8 (essai 
Tableau I. Principales caractéristiques des essais longue durée relatifs à la fertilisation phosphatée.

\begin{tabular}{|c|c|c|c|c|}
\hline & Localisation & Texture de surface & $\begin{array}{c}P_{1} \\
K g P_{2} O_{5} /(\text { ha・an })\end{array}$ & $\begin{array}{c}\text { Statut } P \text { initial } \\
\mathrm{Kg} \mathrm{P}_{2} \mathrm{O}_{5} / \text { ha (année) }\end{array}$ \\
\hline 1 & Jonzac (17) & $\begin{array}{l}\text { Argilo-calcaire } \\
\text { («Terre de Champagne») }\end{array}$ & 56 & $\begin{array}{l}\text { P-JH = } 404 \\
(1971)\end{array}$ \\
\hline 3 & Chaumont (52) & $\begin{array}{l}\text { Limon argileux } \\
\text { («Herbue blanche») }\end{array}$ & 67 & $\begin{array}{c}\text { P-Dyer }=104 \\
(1976)\end{array}$ \\
\hline 7 & $\begin{array}{l}\text { La Chapelle la } \\
\text { Reine (77) Sole } 1\end{array}$ & $\begin{array}{l}\text { Limon } \\
\text { argilo-sableux }\end{array}$ & 62 & $\begin{array}{c}\text { P-Dyer }=245 \\
(1974)\end{array}$ \\
\hline 8 & $\begin{array}{l}\text { La Chapelle la } \\
\text { Reine (77) Sole } 2\end{array}$ & $\begin{array}{l}\text { Limon } \\
\text { argilo-sableux }\end{array}$ & 67 & $\begin{array}{l}\text { P-Dyer }=231 \text { à } 313 \\
(1974)\end{array}$ \\
\hline 9 & Miermaigne (28) & Limon battant & 62 & $\begin{array}{c}\text { P-Dyer }=113 \\
(1976)\end{array}$ \\
\hline 10 & Janvilliers (51) & Limon-argileux & 80 & $\begin{array}{c}\text { P-Dyer }=205 \\
(1975)\end{array}$ \\
\hline 11 & Chalons s/Marne (51) & $\begin{array}{l}\text { Argilo-limoneux } \\
\text { calcaire }\end{array}$ & 80 & $\begin{array}{l}\mathrm{P}-\mathrm{JH}=190 \\
(1975)\end{array}$ \\
\hline 13 & Thure (86) & $\begin{array}{l}\text { Argilo-calcaire } \\
(« \text { Terre d'Aubue») }\end{array}$ & 62 & $\begin{array}{l}\text { P-JH }=220 \\
(1967)\end{array}$ \\
\hline 14 & Champniers (16) & $\begin{array}{l}\text { Argilo-calcaire } \\
\text { («Terre de Grois») }\end{array}$ & 60 & $\begin{array}{l}\text { P-JH }=180 \\
(1968)\end{array}$ \\
\hline 15 & Tusson (16) & $\begin{array}{l}\text { Limon argilo-calcaire } \\
\text { («Terre de Groie») }\end{array}$ & 54 & $\begin{array}{l}\text { P-JH }=175 \\
(1968)\end{array}$ \\
\hline 16 & St Georges de Rex (79) & $\begin{array}{l}\text { Argilo-calcaire ( «Terre } \\
\text { de Grois caillouteuse») }\end{array}$ & 56 & $\begin{array}{l}P-J H=120 \\
(1967)\end{array}$ \\
\hline 17 & Ligre (37) & $\begin{array}{l}\text { Sablo-argilo-calcaire } \\
\text { («Terre d'Aubue) }\end{array}$ & 60 & $\begin{array}{l}\text { P-JH }=225 \\
(1976)\end{array}$ \\
\hline 18 & Vandœuvre (86) & $\begin{array}{l}\text { Limon argileux calcaire } \\
\text { («Terre de Groie») }\end{array}$ & 60 & $\begin{array}{l}\text { P-JH = } 210 \\
(1981)\end{array}$ \\
\hline 20 & Villexanton (41) & Limon argileux & 60 & $\begin{array}{l}\text { P-JH = 98 } \\
(1976)\end{array}$ \\
\hline 21 & Maves (41) & Limon argileux & 60 & $\begin{array}{l}\text { P-JH }=88 \\
(1976)\end{array}$ \\
\hline 22 & Josnes (41) & Limon argileux & 50 & $\begin{array}{l}\text { P-JH = } 155 \\
(1977)\end{array}$ \\
\hline 23 & $\operatorname{Mer}(41)$ & Limon argilo-calcaire & 50 & $\begin{array}{c}\text { P-JH = } 304 \\
(1976)\end{array}$ \\
\hline 32 & Nerac (47) & $\begin{array}{l}\text { Limon argileux } \\
\text { («Boulbène») }\end{array}$ & 71 & $\begin{array}{l}\text { P-Dyer }=106 \\
(1976)\end{array}$ \\
\hline 33 & $\begin{array}{l}\text { Gréoux (04) } \\
\text { enrichi }\end{array}$ & $\begin{array}{l}\text { Argilo-calcaire profond } \\
\text { (alluvions) }\end{array}$ & 80 & $\begin{array}{l}\text { P-JH }=90 \\
(1982)\end{array}$ \\
\hline 34 & $\begin{array}{l}\text { Gréoux (04) } \\
\text { appauvri }\end{array}$ & $\begin{array}{l}\text { Argilo-calcaire profond } \\
\text { (alluvions) }\end{array}$ & 80 & $\begin{array}{l}\text { P-JH }=60 \\
(1982)\end{array}$ \\
\hline 35 & Ennordres (18) & $\begin{array}{l}\text { Sableux à } \\
\text { sablo-limoneux }\end{array}$ & 60 & $\begin{array}{l}\text { P-JH }=240 \\
(1979)\end{array}$ \\
\hline 36 & $\begin{array}{l}\text { Pougny (58) } \\
\text { Sole } 1\end{array}$ & $\begin{array}{l}\text { (Terre d'Aubue) } \\
\text { Argilo-limoneuse }\end{array}$ & 60 & $\begin{array}{c}\text { P-Dyer }=200 \\
(1980)\end{array}$ \\
\hline 37 & $\begin{array}{l}\text { Pougny (58) } \\
\text { Sole } 2\end{array}$ & $\begin{array}{l}\text { Terre d'Aubue } \\
\text { argilo-limoneuse }\end{array}$ & 60 & $\begin{array}{c}\text { P-Dyer }=190 \\
(1979)\end{array}$ \\
\hline 39 & $\begin{array}{l}\text { Tennie }(72) \\
\text { Sole } 1\end{array}$ & $\begin{array}{l}\text { Argilo-limoneux } \\
\text { profond }\end{array}$ & 72 & $\begin{array}{c}\text { P-Dyer }=350 \\
(1978)\end{array}$ \\
\hline 40 & $\begin{array}{l}\text { Tennie (72) } \\
\text { Sole } 2\end{array}$ & $\begin{array}{l}\text { Argilo-limoneux } \\
\text { profond }\end{array}$ & 72 & $\begin{array}{c}\text { P-Dyer }=290 \\
(1978)\end{array}$ \\
\hline 41 & $\begin{array}{l}\text { Herbisse }(10) \\
\text { Sole } 1\end{array}$ & $\begin{array}{l}\text { Craie blanche } \\
\text { du Coniacien }\end{array}$ & 85 & $\begin{array}{l}\text { P-JH }=200 \\
(1981)\end{array}$ \\
\hline 42 & $\begin{array}{l}\text { Herbisse (10) } \\
\text { Sole } 2\end{array}$ & $\begin{array}{l}\text { Craie blanche } \\
\text { du Coniacien }\end{array}$ & 85 & $\begin{array}{c}\text { P-JH }=200 \\
(1981)\end{array}$ \\
\hline 43 & $\begin{array}{l}\text { Guichainville (27) } \\
\text { Sole } 1\end{array}$ & Limoneux & 65 & $\begin{array}{c}\text { P-Dyer }=350 \\
(1978)\end{array}$ \\
\hline
\end{tabular}




\begin{tabular}{|c|c|c|c|c|}
\hline & Localisation & Texture de surface & $\begin{array}{c}\mathrm{Pl} \\
\mathrm{Kg} \mathrm{P}_{2} \mathrm{O}_{5} /(\text { ha・an })\end{array}$ & $\begin{array}{c}\text { Statut } P \text { initial } \\
\mathrm{Kg} \mathrm{P}_{2} \mathrm{O}_{5} / \text { ha (année) }\end{array}$ \\
\hline 44 & $\begin{array}{l}\text { Guichainville (27) } \\
\text { Sol } 2\end{array}$ & Limoneux & 65 & $\begin{array}{c}\text { P-Dyer }=350 \\
(1978)\end{array}$ \\
\hline 47 & Mondouzil (31) & Argilo-limon sableux & 60 & $\begin{array}{c}\text { P-JH }=80 \\
(1977)\end{array}$ \\
\hline 48 & St Médard (36) & Limon sableux & 70 & $\begin{array}{c}\text { P-Dyer }=95 \\
(1979)\end{array}$ \\
\hline 49 & Villechauve (41) & Limon & 60 & $\begin{array}{c}\text { P-Dyer }=108 \\
(1977)\end{array}$ \\
\hline 50 & Neuilly (89) & $\begin{array}{l}\text { Argilo-calcaire } \\
\text { superficiel }\end{array}$ & 107 & $\begin{array}{l}\text { P-JH = } 130 \\
(1964)\end{array}$ \\
\hline 51 & Gigny (89) & Limono-argileux & 99 & $\begin{array}{c}\text { P-Dyer }=70 \\
(1965)\end{array}$ \\
\hline 63 & Castelnaudary (11) & $\begin{array}{l}\text { Limoneux à argilo- } \\
\text { limoneux }\end{array}$ & 60 & $\begin{array}{c}P-J H=80 \\
(1973)\end{array}$ \\
\hline 65 & Clermont-Ferrand (63) & Limon argilo-calcaire & 53 & $\begin{array}{c}\text { P-Dyer }=700 \\
(1949)\end{array}$ \\
\hline 66 & Castanet-Tolosan (31) & Argilo-limoneux & 40 & $\begin{array}{l}\text { P-Dyer }=50 \text { à } 150 \\
(1969)\end{array}$ \\
\hline 78 & $\begin{array}{l}\text { Grignon (78) } \\
\text { Folleville } 4\end{array}$ & $\begin{array}{l}\text { Limon argileux } \\
(1958)\end{array}$ & 43 & P-JH $=180$ \\
\hline 79 & $\begin{array}{l}\text { Grignon (78) } \\
\text { Folleville } 7\end{array}$ & $\begin{array}{l}\text { Limon argileux } \\
(1958)\end{array}$ & 31 & P-JH $=180$ \\
\hline 80 & $\begin{array}{l}\text { Grignon (78) } \\
\text { Folleville } 2\end{array}$ & Limon argileux & $\begin{array}{c}P_{1}=\text { absent } \\
P_{2}=100\end{array}$ & $\begin{array}{l}\text { P-JH = } 180 \\
(1958)\end{array}$ \\
\hline
\end{tabular}

50 en 1976) et 90,7 décitonnes (dt) par hectare (essai 79 en 1988). Les variations de rendement entre site et année sont supérieures à celles imputables aux traitements phosphore dans un essai pour une année donnée. L'explication réside dans la multiplicité des facteurs déterminant le niveau de la production finale, tels que le choix de la variété, les conditions pédoclimatiques, les pratiques culturales...

L'analyse essai par essai des rendements du blé en fonction du régime de fertilisation phosphatée permet, pour les 55 couples essais $x$ années, de dégager 2 observations. Premièrement, les rendements en grain mesurés pour le niveau d'apport $P_{2}$ diffèrent significativement (seuil de $5 \%$ ) de ceux de $P_{1}$, dans 3 situations : essais 13 , 48 et 66 . Dans l'essai 13 , bien que statisquement significatif, le gain de rendement mesuré

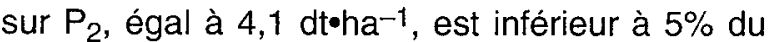
rendement obtenu pour $P_{1}$ et n'est pas reproductible dans le temps. Dans les essais 48 et 66 , le gain de rendement est respectivement de 11,5 et $13,6 \%$ du rendement obtenu sur $P_{1}$ et est expliqué par des teneurs inférieures à $65 \mathrm{mg}$ $\mathrm{P}_{2} \mathrm{O}_{5} \bullet$ ha $^{-1}$ en phosphore extractible par la méthode Dyer du traitement $P_{1}$. Deuxièmement, les rendements en grain mesurés sur $P_{0}$ sont signifi- cativement inférieures à ceux du traitement $P_{1}$ dans 21 situations.

\section{Le statut phosphaté du sol}

Les données analytiques sont présentées dans le tableau II. Le niveau de phosphore révélé à l'analyse varie selon les méthodes suivant un ordre identique à celui observé antérieurement pour les méthodes chimiques (Gachon, 1969; Boniface et Trocmé, 1988) : Dyer > Joret-Hebert $>$ Olsen $>E_{\text {Pie1 }}$. Ce résultat illustre le fait que les réactifs chimiques sont d'agressivité variable vis-à-vis des phosphates du sol et extraient du phosphore qui n'est pas en totalité sous une forme directement accessible pour les plantes puisque les quantités extraites par les méthodes chimiques sont toujours supérieures aux valeurs de $E_{\text {pie1 }}$ (Fardeau et al, 1988).

\section{Relations entre le rendement en grain du blé et le statut phosphaté du sol}

Les paramètres $b$ et $c$ de l'équation $I R=100-b x$ $\exp (-c \times$ Pass $)$, où Pass désigne les quantités 
Tableau II. Rendement en grain de la culture de blé et statut phosphaté des échantillons de sol issus des essais longue durée sur la fertilisation phosphatée. Les données sont issues des publications de Boniface et Trocmé (1988), Martinez et Delas (1990); Castillon (1991), Fardeau (1991), Morel et Plenchette (1991).

\begin{tabular}{|c|c|c|c|c|c|c|c|}
\hline \multirow{2}{*}{$\begin{array}{l}\text { Réf } \\
\text { essai }\end{array}$} & \multirow{2}{*}{$\begin{array}{l}\text { Année de } \\
\text { culture }\end{array}$} & \multirow{2}{*}{$\begin{array}{l}\text { Fertilisation } \\
\text { phosphatée }\end{array}$} & \multirow{2}{*}{$\begin{array}{l}\text { Rendement } \\
(d t a / h a)\end{array}$} & \multicolumn{4}{|c|}{ Statut phosphaté } \\
\hline & & & & P-Dyer & $P-J H\left(m g P_{2} O_{5} / k g\right)$ & P-Olsen & $E_{P i e 1}$ \\
\hline 1 & $\begin{array}{l}1983 \\
1984\end{array}$ & $\begin{array}{l}P_{0} \\
P_{1} \\
P_{2} \\
P_{0} \\
P_{1} \\
P_{2}\end{array}$ & $\begin{array}{l}59,8 \mathrm{NS}^{b} \\
57,6 \\
54,0 \mathrm{NS} \\
45,1 \mathrm{~S} \\
52,6 \\
54,5 \mathrm{NS}\end{array}$ & $\begin{array}{l}- \\
- \\
- \\
- \\
- \\
-\end{array}$ & $\begin{array}{l}360 \\
436 \\
584 \\
360 \\
436 \\
584\end{array}$ & $\begin{array}{l}- \\
- \\
- \\
- \\
- \\
-\end{array}$ & $\begin{array}{l}- \\
- \\
- \\
- \\
- \\
-\end{array}$ \\
\hline 3 & 1986 & $\begin{array}{l}P_{0} \\
P_{1} \\
P_{2}\end{array}$ & $\begin{array}{l}59,5 \mathrm{NS} \\
62,3 \\
63,5 \mathrm{NS}\end{array}$ & $\begin{array}{r}71 \\
129 \\
186\end{array}$ & $\begin{array}{l}- \\
- \\
-\end{array}$ & $\begin{array}{l}39 \\
63 \\
90\end{array}$ & $\begin{array}{l}11,5 \\
16,7 \\
34,4\end{array}$ \\
\hline 7 & 1987 & $\begin{array}{l}P_{0} \\
P_{1} \\
P_{2}\end{array}$ & $\begin{array}{l}63,1 \mathrm{~S} \\
74,8 \\
75,4 \mathrm{NS}\end{array}$ & $\begin{array}{l}153 \\
300 \\
186\end{array}$ & $\begin{array}{l}- \\
- \\
-\end{array}$ & $\begin{array}{r}23 \\
81 \\
148\end{array}$ & $\begin{array}{l}- \\
- \\
-\end{array}$ \\
\hline 8 & 1988 & $\begin{array}{l}P_{0} \\
P_{1} \\
P_{2}\end{array}$ & $\begin{array}{l}83,0 \mathrm{NS} \\
83,8 \\
88,0 \mathrm{NS}\end{array}$ & $\begin{array}{l}161 \\
308 \\
450\end{array}$ & $\begin{array}{l}- \\
- \\
-\end{array}$ & $\begin{array}{r}54 \\
114 \\
183\end{array}$ & $\begin{array}{l}- \\
-\end{array}$ \\
\hline 9 & $\begin{array}{l}1988 \\
1989\end{array}$ & $\begin{array}{l}P_{0} \\
P_{1} \\
P_{2} \\
P_{0} \\
P_{1} \\
P_{2}\end{array}$ & $\begin{array}{l}59,5 \text { NS } \\
61,5 \\
59,9 \text { NS } \\
50,3 \mathrm{~S} \\
63,8 \\
67,8 \text { NS }\end{array}$ & $\begin{array}{r}63 \\
116 \\
188 \\
63 \\
116 \\
188\end{array}$ & $\begin{array}{r}30 \\
65 \\
128 \\
30 \\
65 \\
128\end{array}$ & $\begin{array}{l}20 \\
39 \\
67 \\
20 \\
39 \\
67\end{array}$ & $\begin{array}{r}3,7 \\
9,6 \\
31,8 \\
3,7 \\
9,6 \\
31,8\end{array}$ \\
\hline 10 & 1987 & $\begin{array}{l}P_{0} \\
P_{1} \\
P_{2}\end{array}$ & $\begin{array}{l}66,0 \mathrm{NS} \\
67,8 \\
66,5 \mathrm{NS}\end{array}$ & $\begin{array}{l}200 \\
270 \\
340\end{array}$ & $\begin{array}{l}- \\
- \\
-\end{array}$ & $\begin{array}{r}59 \\
107 \\
143\end{array}$ & $\begin{array}{l}16,5 \\
33,2 \\
54,7\end{array}$ \\
\hline 11 & 1987 & $\begin{array}{l}P_{0} \\
P_{1} \\
P_{2}\end{array}$ & $\begin{array}{l}56,3 \text { NS } \\
66,5 \\
62,7 \text { NS }\end{array}$ & $\begin{array}{l}- \\
- \\
-\end{array}$ & $\begin{array}{l}141 \\
211 \\
250\end{array}$ & $\begin{array}{l}- \\
- \\
-\end{array}$ & $\begin{array}{l}- \\
-\end{array}$ \\
\hline 13 & 1989 & $\begin{array}{l}P_{0} \\
P_{1} \\
P_{2} \\
P_{0}\end{array}$ & $\begin{array}{l}48,9 \mathrm{~S} \\
53,9 \\
53,3 \mathrm{NS} \\
46,8 \mathrm{~S}\end{array}$ & $\begin{array}{l}- \\
- \\
- \\
-\end{array}$ & $\begin{array}{l}186 \\
250 \\
360 \\
163\end{array}$ & $\begin{array}{l}21 \\
52 \\
79 \\
37\end{array}$ & $\begin{array}{l}- \\
- \\
- \\
-\end{array}$ \\
\hline 14 & 1977 & $\begin{array}{l}P_{0} \\
P_{1} \\
P_{2} \\
P_{0} \\
P_{1} \\
P_{2}\end{array}$ & $\begin{array}{l}36,5 \mathrm{NS} \\
37,6 \\
38,0 \mathrm{NS} \\
49,5 \mathrm{NS} \\
48,2 \\
48,5 \mathrm{NS}\end{array}$ & $\begin{array}{l}- \\
- \\
- \\
- \\
- \\
-\end{array}$ & $\begin{array}{l}105 \\
198 \\
269 \\
107 \\
190 \\
328\end{array}$ & $\begin{array}{r}36 \\
92 \\
134 \\
40 \\
92 \\
140\end{array}$ & $\begin{array}{l}- \\
- \\
- \\
- \\
- \\
-\end{array}$ \\
\hline 15 & 1978 & $\begin{array}{l}P_{0} \\
P_{1} \\
P_{2} \\
P_{0} \\
P_{1} \\
P_{2}\end{array}$ & $\begin{array}{l}75,8 \text { NS } \\
80,3 \\
78,8 \text { NS } \\
68,2 \text { NS } \\
66,3 \\
70,0 \text { NS }\end{array}$ & $\begin{array}{l}- \\
- \\
- \\
- \\
-\end{array}$ & $\begin{array}{r}95 \\
185 \\
254 \\
118 \\
220 \\
310\end{array}$ & $\begin{array}{r}41 \\
96 \\
127 \\
- \\
- \\
-\end{array}$ & $\begin{array}{l}- \\
- \\
- \\
- \\
-\end{array}$ \\
\hline
\end{tabular}


Réf Année de Fertilisation essai culture phosphatée
Rendement

(dt a/ha)

58,7 NS

61,0

60,9 NS

63,5 NS

68,1

66,9 NS

56,1 NS

60,3

61,1 NS

70,9 NS

71,3

73,0 NS

$53,2 \mathrm{~S}$

61,7

62,1 NS

$63,6 \mathrm{~S}$

68,2

67,2 NS

68,1 NS

67,3

70,3 NS

62,5 NS

62,1

64,7 NS

68,5 NS

68,0

71,6 NS

49,6 NS

52,7

55,4 NS

55,1 NS

52,8

53,7 NS

$58,1 \mathrm{~S}$

67,0

67,9 NS

$47,0 \mathrm{~S}$

66,3

64,3 NS

72,0 NS

67,3

70,5 NS

71,2 NS

73,8

72,2 NS
Statut phosphaté

P-Dyer P-JH( $\left.\mathrm{mg} \mathrm{P}_{2} \mathrm{O}_{5} / \mathrm{kg}\right)$ P-Olsen $\quad E_{\text {Pie1 }}$

$\begin{array}{lr}- & 91 \\ - & 140 \\ - & 210 \\ - & 210 \\ - & 247 \\ - & 307 \\ - & 180 \\ - & 220 \\ - & 260\end{array}$

- 48

100

$-145$

41
77

150

$-\quad 52$

- $\quad 81$

118

52

$\begin{array}{rr}- & 81 \\ - & 118\end{array}$

$\begin{array}{lr}- & 81 \\ - & 118\end{array}$

37
75

117

17

$\begin{array}{ll}47 & 26 \\ 07 & 50\end{array}$

80

20

0

$-$

86

150

190

86

150

190

217

266

281

217

266

281

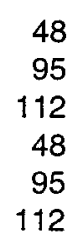

112
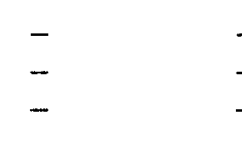

-

-

62

103

130

62

103

130

40

108

173

$\begin{array}{ll}- & 70 \\ - & 80\end{array}$

70
80

71

19

28

6,2

7,6

12,4

60
70

80

6
11

5,3

6,0

20

8,2

180

230

270

90

140

200 


\begin{tabular}{|c|c|c|c|c|c|c|c|}
\hline \multirow{2}{*}{$\begin{array}{l}\text { Réf } \\
\text { essai }\end{array}$} & \multirow{2}{*}{$\begin{array}{l}\text { Année de } \\
\text { culture }\end{array}$} & \multirow{2}{*}{$\begin{array}{l}\text { Fertilisation } \\
\text { phosphatée }\end{array}$} & \multirow{2}{*}{$\begin{array}{l}\text { Rendement } \\
(d t \mathrm{a} / \mathrm{ha})\end{array}$} & \multicolumn{4}{|c|}{ Statut phosphaté } \\
\hline & & & & $P$-Dyer & $P$-JH $\left(m g P_{2} O_{5} / k g\right)$ & P-Olsen & $E_{P i e 1}$ \\
\hline 37 & 1988 & $\begin{array}{l}P_{0} \\
P_{1} \\
P_{2}\end{array}$ & $\begin{array}{l}70,5 \text { NS } \\
65,5 \\
72,9 \text { NS }\end{array}$ & $\begin{array}{l}120 \\
200 \\
270\end{array}$ & $\begin{array}{l}- \\
- \\
-\end{array}$ & $\begin{array}{l}- \\
- \\
-\end{array}$ & $\begin{array}{l}- \\
- \\
-\end{array}$ \\
\hline 39 & 1987 & $\begin{array}{l}P_{0} \\
P_{1} \\
P_{2}\end{array}$ & $\begin{array}{l}85,3 \text { NS } \\
84,7 \\
86,4 \text { NS }\end{array}$ & $\begin{array}{l}220 \\
270 \\
310\end{array}$ & $\begin{array}{l}- \\
- \\
-\end{array}$ & $\begin{array}{r}76 \\
96 \\
128\end{array}$ & $\begin{array}{l}31,6 \\
42,1 \\
55,0\end{array}$ \\
\hline 40 & 1986 & $\begin{array}{l}P_{0} \\
P_{1} \\
P_{2}\end{array}$ & $\begin{array}{l}72,9 \text { NS } \\
67,9 \\
71,1 \text { NS }\end{array}$ & $\begin{array}{l}190 \\
250 \\
250\end{array}$ & $\begin{array}{l}- \\
- \\
-\end{array}$ & $\begin{array}{l}- \\
- \\
-\end{array}$ & $\begin{array}{l}- \\
- \\
-\end{array}$ \\
\hline 41 & 1986 & $\begin{array}{l}P_{0} \\
P_{1} \\
P_{2}\end{array}$ & $\begin{array}{l}66,0 \mathrm{~S} \\
73,2 \\
75,1 \text { NS }\end{array}$ & $\begin{array}{l}- \\
- \\
-\end{array}$ & $\begin{array}{l}130 \\
190 \\
250\end{array}$ & $\begin{array}{l}- \\
- \\
-\end{array}$ & $\begin{array}{l}19,9 \\
26,3 \\
38,2\end{array}$ \\
\hline 42 & 1985 & $\begin{array}{l}\mathrm{P}_{0} \\
\mathrm{P}_{1} \\
\mathrm{P}_{2}\end{array}$ & $\begin{array}{l}64,7 \mathrm{~S} \\
72,7 \\
71,4 \mathrm{NS}\end{array}$ & $\begin{array}{l}- \\
- \\
-\end{array}$ & $\begin{array}{l}120 \\
170 \\
245\end{array}$ & $\begin{array}{l}- \\
- \\
-\end{array}$ & $\begin{array}{l}- \\
-\end{array}$ \\
\hline 43 & 1988 & $\begin{array}{l}P_{0} \\
P_{1} \\
P_{2}\end{array}$ & $\begin{array}{l}86,7 \text { NS } \\
89,0 \\
89,0\end{array}$ & $\begin{array}{l}- \\
- \\
-\end{array}$ & $\begin{array}{l}260 \\
345 \\
345\end{array}$ & $\begin{array}{l}- \\
- \\
-\end{array}$ & $\begin{array}{l}- \\
- \\
-\end{array}$ \\
\hline 44 & 1986 & $\begin{array}{l}P_{0} \\
P_{1} \\
P_{2}\end{array}$ & $\begin{array}{l}69,9 \mathrm{~S} \\
72,8 \\
72,5 \mathrm{NS}\end{array}$ & $\begin{array}{l}- \\
- \\
-\end{array}$ & $\begin{array}{l}300 \\
390 \\
440\end{array}$ & $\begin{array}{l}- \\
- \\
-\end{array}$ & $\begin{array}{l}- \\
- \\
-\end{array}$ \\
\hline 47 & 1982 & $\begin{array}{l}P_{0} \\
P_{1} \\
P_{2}\end{array}$ & $\begin{array}{l}52,4 \mathrm{NS} \\
54,0 \\
54,2 \mathrm{NS}\end{array}$ & $\begin{array}{l}- \\
- \\
-\end{array}$ & $\begin{array}{l}67 \\
67 \\
85\end{array}$ & $\begin{array}{l}- \\
- \\
-\end{array}$ & $\begin{array}{l}- \\
- \\
-\end{array}$ \\
\hline 48 & 1986 & $\begin{array}{l}P_{0} \\
P_{1} \\
P_{2}\end{array}$ & $\begin{array}{l}32,5 \mathrm{~S} \\
45,1 \\
50,3 \mathrm{~S}\end{array}$ & $\begin{array}{r}40 \\
65 \\
120\end{array}$ & $\begin{array}{l}- \\
- \\
-\end{array}$ & $\begin{array}{l}- \\
- \\
-\end{array}$ & $\begin{array}{l}- \\
- \\
-\end{array}$ \\
\hline 49 & 1983 & $\begin{array}{l}P_{0} \\
P_{1} \\
P_{2} \\
P_{0} \\
P_{1} \\
P_{2}\end{array}$ & $\begin{array}{l}60,8 \mathrm{NS} \\
63,9 \\
63,8 \mathrm{NS} \\
63,5 \mathrm{~S} \\
69,5 \\
70,9 \mathrm{NS}\end{array}$ & $\begin{array}{r}80 \\
145 \\
155 \\
80 \\
145 \\
155 \\
80\end{array}$ & $\begin{array}{l}- \\
- \\
- \\
- \\
- \\
-\end{array}$ & $\begin{array}{l}- \\
- \\
- \\
- \\
- \\
-\end{array}$ & $\begin{array}{l}- \\
- \\
- \\
- \\
- \\
-\end{array}$ \\
\hline 50 & 1976 & $\begin{array}{l}\mathrm{P}_{0} \\
\mathrm{P}_{2}\end{array}$ & $\begin{array}{l}23,7 \mathrm{~S} \\
34,0\end{array}$ & $\begin{array}{l}28,8 \\
160\end{array}$ & - & - & - \\
\hline 51 & 1972 & $\begin{array}{l}P_{0} \\
P_{1} \\
P_{2}\end{array}$ & $\begin{array}{l}40,6 \text { NS } \\
41,3 \\
41,6 \text { NS }\end{array}$ & $\begin{array}{r}55 \\
100 \\
130\end{array}$ & - & $\begin{array}{l}- \\
- \\
-\end{array}$ & $\begin{array}{l}- \\
- \\
-\end{array}$ \\
\hline & 1975 & $\begin{array}{l}P_{0} \\
P_{1}\end{array}$ & $\begin{array}{l}28,6 \mathrm{~S} \\
33,8\end{array}$ & $\begin{array}{r}40 \\
120\end{array}$ & - & $\begin{array}{l}- \\
-\end{array}$ & $\begin{array}{l}- \\
-\end{array}$ \\
\hline & 1978 & $\begin{array}{l}\mathrm{P}_{2} \\
\mathrm{P}_{0}\end{array}$ & $\begin{array}{l}35,1 \mathrm{NS} \\
31,5 \mathrm{~S}\end{array}$ & $\begin{array}{r}155 \\
40\end{array}$ & - & - & - \\
\hline & 1981 & $\begin{array}{l}P_{2} \\
P_{0} \\
P_{1} \\
P_{2}\end{array}$ & $\begin{array}{l}42,1 \\
28,8 \mathrm{~S} \\
53,4 \\
54,7 \text { NS }\end{array}$ & $\begin{array}{r}120 \\
20 \\
80 \\
120\end{array}$ & $\begin{array}{l}- \\
- \\
-\end{array}$ & $\begin{array}{l}- \\
- \\
- \\
-\end{array}$ & $\begin{array}{l}- \\
- \\
- \\
-\end{array}$ \\
\hline
\end{tabular}




\begin{tabular}{|c|c|c|c|c|c|c|c|}
\hline \multirow{2}{*}{$\begin{array}{l}\text { Réf } \\
\text { essai }\end{array}$} & \multirow{2}{*}{$\begin{array}{l}\text { Année de } \\
\text { culture }\end{array}$} & \multirow{2}{*}{$\begin{array}{l}\text { Fertilisation } \\
\text { phosphatée }\end{array}$} & \multirow{2}{*}{$\begin{array}{l}\text { Rendement } \\
\text { (dt a/ha) }\end{array}$} & \multicolumn{4}{|c|}{ Statut phosphaté } \\
\hline & & & & $P$-Dyer & $P-J H\left(m g P_{2} O_{5} / k g\right)$ & P-Olsen & $E_{\text {Piet }}$ \\
\hline \multirow[t]{3}{*}{63} & 1978 & $P_{0}$ & $35,1 \mathrm{NS}$ & 99 & 53 & 25 & 14,0 \\
\hline & & $P_{1}$ & 39,0 & 142 & 83 & 43 & 16,7 \\
\hline & & $P_{2}$ & $36,6 \mathrm{NS}$ & 161 & 98 & 50 & 22,0 \\
\hline \multirow[t]{2}{*}{65} & 1978 & $P_{0}$ & 45,4 NS & 680 & 342 & 35 & - \\
\hline & & $P_{2}$ & 42,9 & 760 & 408 & 58 & - \\
\hline \multirow[t]{3}{*}{66} & 1977 & $P_{0}$ & $48,9 \mathrm{~S}$ & 40 & 20 & 7 & - \\
\hline & & $P_{1}$ & 66,1 & 47 & 43 & 16 & - \\
\hline & & $\mathrm{P}_{2}$ & $75,1 \mathrm{~S}$ & 93 & 73 & 30 & - \\
\hline \multirow[t]{6}{*}{78} & 1988 & $P_{0}$ & 88,2 NS & - & - & 16 & 4,8 \\
\hline & & $P_{1}$ & 89,7 & - & - & 80 & 34,8 \\
\hline & & $P_{2}$ & 90,8 NS & - & - & 108 & 49,9 \\
\hline & 1990 & $P_{0}$ & $77,0 \mathrm{NS}$ & - & - & 16 & 4,8 \\
\hline & & $P_{1}$ & 80,6 & - & - & 80 & 34,8 \\
\hline & & $\mathrm{P}_{2}$ & 80,6 NS & - & - & 108 & 49,9 \\
\hline \multirow[t]{6}{*}{79} & 1988 & $P_{0}$ & $91,0 \mathrm{NS}$ & - & - & 38 & 11,0 \\
\hline & & $P_{1}$ & 90,8 & - & - & 66 & 27,5 \\
\hline & & $P_{2}$ & $90,3 \mathrm{NS}$ & - & - & 142 & 70,5 \\
\hline & 1990 & $P_{0}^{c}$ & 86,2 NS & - & - & 38 & 11,0 \\
\hline & & $P_{1}$ & 84,6 & - & - & 66 & 27,5 \\
\hline & & $P_{2}$ & $84,5 \mathrm{NS}$ & - & - & 142 & 70,5 \\
\hline \multirow[t]{4}{*}{80} & 1988 & $P_{0}$ & $55,8 \mathrm{~S}$ & - & - & 10 & 2,3 \\
\hline & & $P_{2}$ & 66,9 & - & - & 87 & 40,5 \\
\hline & 1990 & $P_{0}$ & $67,4 \mathrm{~S}$ & - & - & 10 & 2,3 \\
\hline & & $\mathrm{P}_{2}$ & 78,6 & - & - & 87 & 40,5 \\
\hline
\end{tabular}

a $\mathrm{dt} /$ ha : décitonne par hectare; ${ }^{\mathrm{b}}$ seuil de signification : rendement non significativement différent (NS) ou significativement différent (S) de celui obtenu sur $\mathrm{P}_{1}(P=0,05)$.

Tableau III. Paramètres $b, c$ de l'équation $I R=100-b$ $x \exp (-c \times$ Pass), où Pass désigne la quantité de $P$ du sol déterminée par analyse et $I R$ l'indice de rendement. $R^{2}$ et $n$ désignent respectivement le pourcentage d'explication de la variabilité expérimentale par le modèle et le nombre d'essais utilisés dans l'analyse statistique.

\begin{tabular}{lcccc}
\hline Critère analytique & $\mathrm{b}$ & $\mathrm{c}$ & $\mathrm{R}^{2}$ & $\mathrm{n}$ \\
& & & & \\
\hline P-Dyer & 81,4 & 0,031 & 0,61 & 18 \\
P-JH & 70,2 & 0,036 & 0,39 & 24 \\
P-Olsen & 36,4 & 0,070 & 0,44 & 22 \\
EPie1 & 37,8 & 0,535 & 0,53 & 11 \\
\hline
\end{tabular}

Fig 1. Relation entre le rendement relatif en grain du blé (IR) et la quantité de phosphore extrait du sol par la méthode Dyer (P-Dyer).
$I R(\%)$

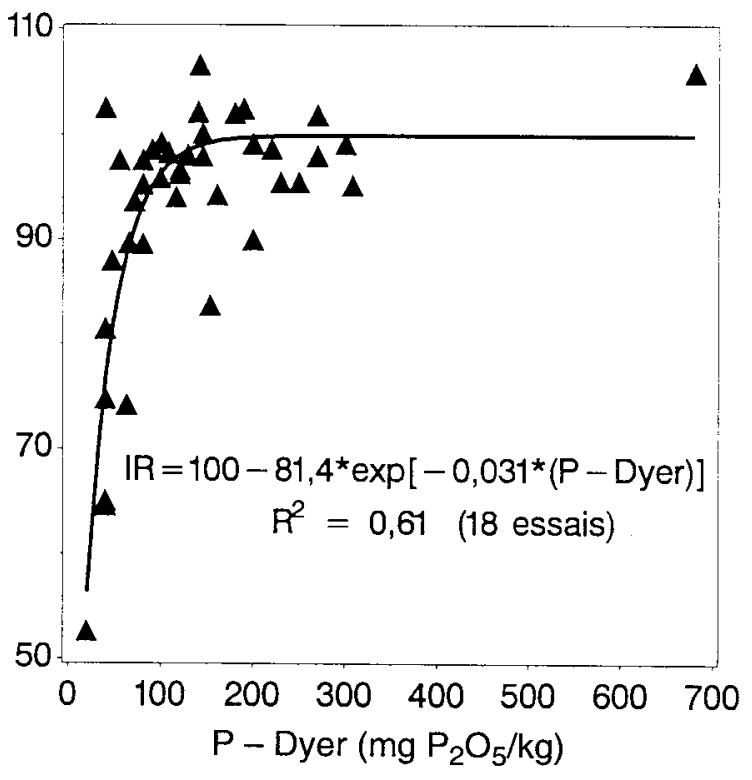


de phosphore déterminées par les analyses chimiques ou isotopique sont présentés dans le tableau III. Les figures 1, 2, 3 et 4 présentent les données expérimentales et les relations statistiques pour, respectivement, les méthodes Dyer, Joret-Hébert, Olsen et isotopique. Chacune des équations permet d'expliquer d'après le $\mathrm{R}^{2}$ environ $50 \%$ de la variabilité expérimentale (tableau

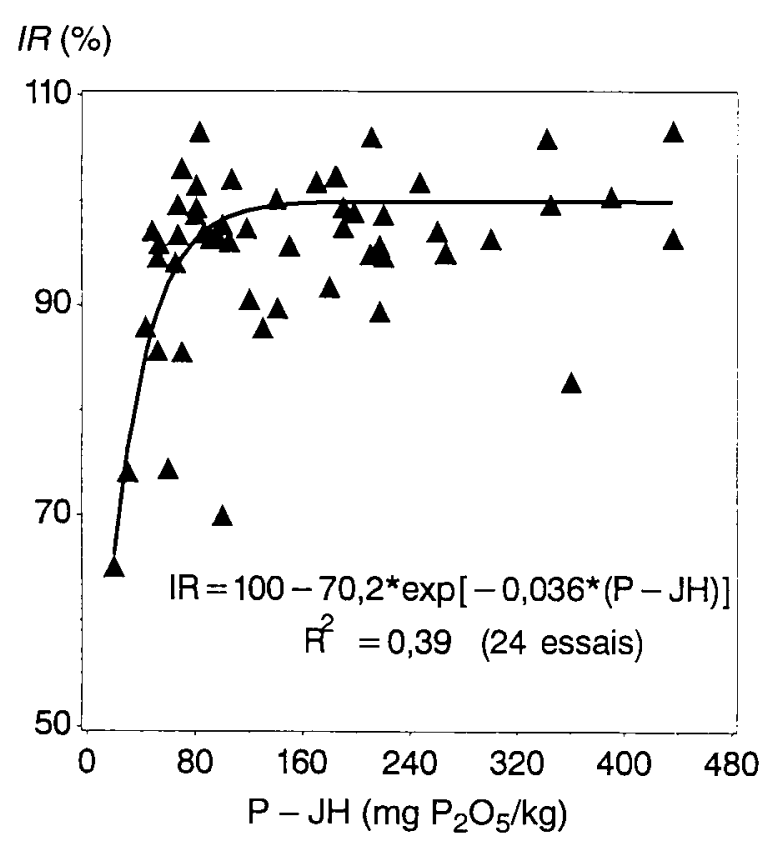

Fig 2. Relation entre le rendement relatif en grain du blé (IR) et la quantité de phosphore extrait du sol par la méthode Joret-Hébert $(P-J H)$.

$\operatorname{IR}(\%)$

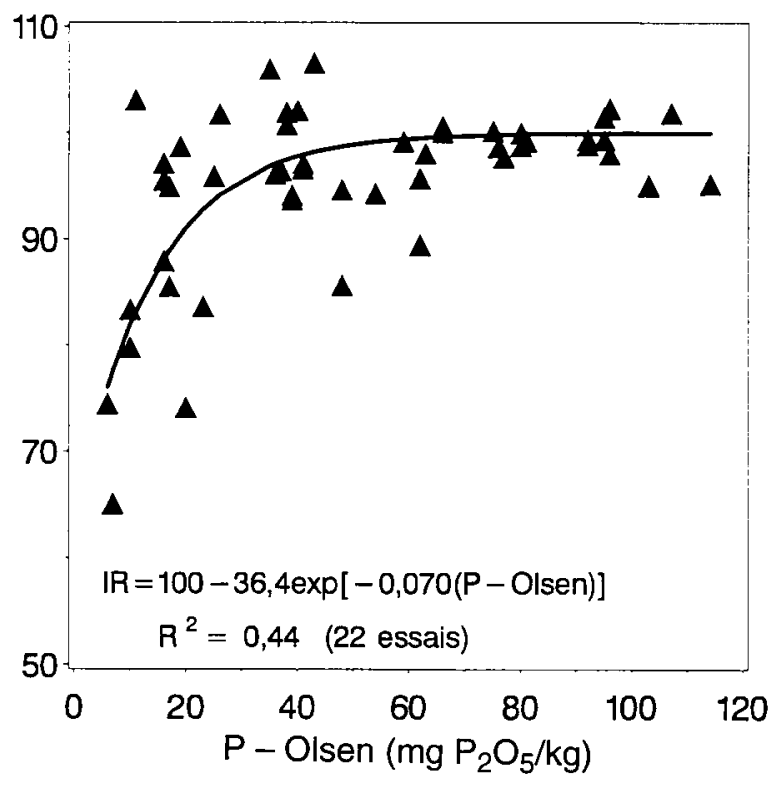

Fig 3. Relation entre le rendement relatif en grain du blé (IR) et la quantité de phosphore extrait du sol par la méthode Olsen (P-Olsen).

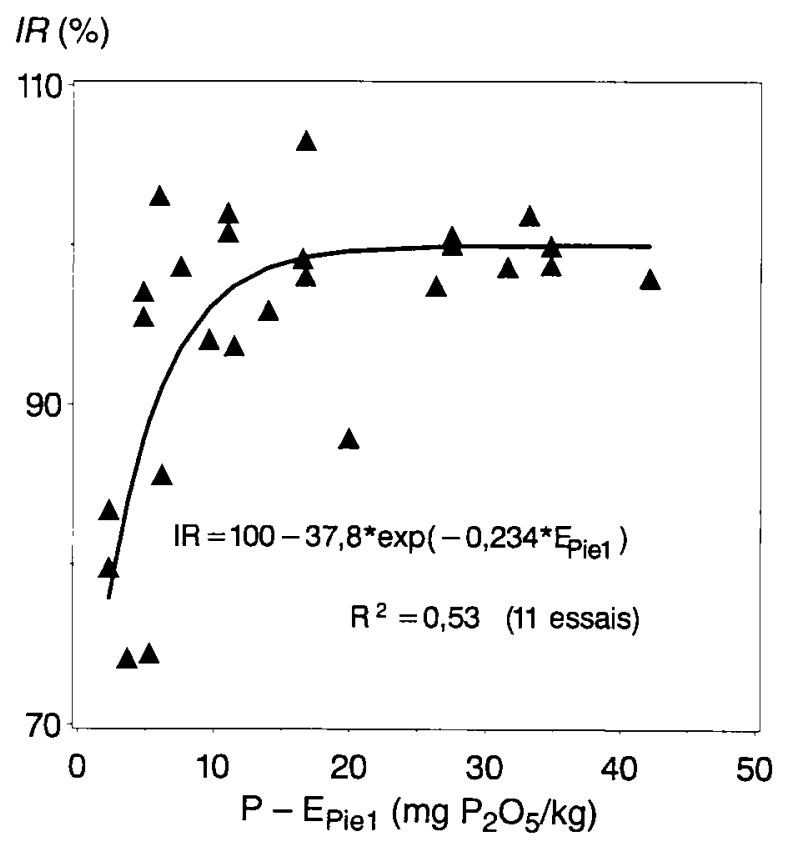

Fig 4. Relation entre le rendement relatif en grain du blé (IR) et la quantité de phosphore du sol isotopiquement échangeable en 1 min $\left(E_{\text {Pie1 } 1}\right)$.

III), ce qui est conforme aux valeurs publiées. Un classement des différentes techniques basé sur la valeur du $R^{2}$ ne peut néanmoins être réalisé puisque le nombre des essais et les essais utilisés pour l'analyse statistique sont différents suivant les méthodes d'appréciation du statut $P$.

\section{Statut phosphaté du sol et niveau d'entretien}

À partir des relations précédentes, il est possible de calculer les niveaux de phosphore extractible du sol permettant d'obtenir n'importe quelle valeur souhaitée de l'indice de rendement IR. Le tableau IV présente les niveaux analytiques associés à l'obtention de $90 \%, 95 \%$ et $98,5 \%$ du

Tableau IV. Valeurs calculées des quantités P-Dyer, P-JH, P-Olsen et $E_{P i e 1}$ pour des indices de rendements égaux à $90 \%, 95 \%$ et $98,5 \%$ du rendement optimal en grain.

\begin{tabular}{lccc}
$\begin{array}{l}\text { Statut phosphaté } \\
\left(\mathrm{mg} \mathrm{P}_{2} \mathrm{O}_{5} / \mathrm{kg}\right)\end{array}$ & IR $90 \%$ & IR $95 \%$ & IR $98,5 \%$ \\
\hline & & & \\
P-Dyer & 68 & 90 & 129 \\
P-JH & 54 & 73 & 107 \\
P-OIsen & 18 & 28 & 45 \\
E & 5,7 & 8,7 & 13,7 \\
& & & \\
\hline
\end{tabular}


rendement en grain obtenu dans des conditions optimales de nutrition phosphatée. Ces 3 niveaux ont été retenus car ils représentent 3 réalités agronomiques différentes :

- un IR de $90 \%$ correspond à une différence de rendement hautement significative, ce qui justifie l'emploi d'engrais phosphaté;

- la valeur de $95 \%$ est en général à la limite de signification statistique d'un essai agronomique de plein champ; il en résulte que le niveau du statut phosphaté correspondant à cette valeur est le niveau pour lequel la culture de blé ne réagit pas significativement à un apport d'engrais phosphaté; ce niveau de réserves en phosphore assimilable est appelé, pour reprendre la terminologie précédemment définie, niveau d'entretien du statut phosphaté du sol pour la culture de blé;

- une variation de $I R$ égale à $1,5 \%$ n'est pas statistiquement significative en terme de rendement biologique et n'est pas économiquement justifiable puisque le coût du passage d'un régime de fertilisation de $\mathrm{P}_{1}$ à $\mathrm{P}_{2}$, soit $64 \mathrm{~kg} \mathrm{P}_{2} \mathrm{O}_{5} \bullet$ ha ${ }^{-1}$ en moyenne sur les essais utilisés, est égal à 210 $\mathrm{FF} \bullet \mathrm{ha}^{-1}$, en retenant une valeur de $3,30 \mathrm{FF}$ pour le $\mathrm{kg} \mathrm{P}_{2} \mathrm{O}_{5}$ épandu, pour un supplément de recettes égal à $1,5 \mathrm{dt \bullet ha-1}$ soit $150 \mathrm{FF}^{-} \mathrm{Fha}^{-1}$ pour une culture intensive de blé.

Les valeurs seuils, exprimées en mg $\mathrm{P}_{2} \mathrm{O}_{5}{ }^{\circ \mathrm{kg}^{-1}}$ sol, correspondant à l'obtention de $I R=95 \%$, sont de 90 pour la méthode Dyer, 73 pour la méthode Joret-Hébert, 28 pour la méthode Olsen et 8,7 pour $\mathrm{E}_{\text {Pie1. }}$.

À l'exception d'informations, publiées récemment par nous-mêmes (Fardeau et al, 1991), la littérature ne permet pas de comparer la valeur seuil proposée pour $\mathrm{E}_{\mathrm{Pie} 1}$ à d'autres propositions. Cependant, l'équation [1] permet d'estimer la valeur qu'aurait $C p$ si $r / R$ était connu. Pour des sols de grande culture tels que ceux utilisés dans le cadre de ce travail, la valeur de $\pi / R$ se situe en moyenne aux alentours de 0,25 (Fardeau et al, 1991). La valeur estimée de Cp est alors de $0,22 \mathrm{mg} \mathrm{P}_{2} \mathrm{O}_{5} \bullet-1$ soit $0,095 \mathrm{mg}$ $\mathrm{P} \cdot 1-1$. Cette valeur correspond à une extraction dans l'eau et serait en moyenne 4 fois plus faible si l'extraction était réalisée dans du $\mathrm{CaCl}_{2}$ $10^{-2} \mathrm{M}$ (Fardeau et al, 1988), soit de l'ordre de $0,024 \mathrm{mg} \mathrm{P \bullet l-1}$. Cette valeur estimée de $C p$ est équivalente à celle publiée par Memon et Fox (1983) pour la culture du blé réalisée dans un contexte pédo-climatique totalement différent de celui de la France. L'estimation de la valeur seuil pour $E_{P i e 1}$ paraît donc vraisemblable.
La valeur seuil $\mathrm{P}$-Olsen $=28 \mathrm{mg} \mathrm{P}_{2} \mathrm{O}_{5}{ }^{\circ} \mathrm{kg}^{-1}$ sol correspondant à un $I R$ de $95 \%$ peut être comparée à celles précédemment citées d'une part par Nelson et Anderson (1980) et Azzaoui et al (1989) : $16 \mathrm{mg} \mathrm{P}_{2} \mathrm{O}_{5}{ }^{\circ} \mathrm{kg}^{-1}$ pour $80 \%$ du rendement optimal, et d'autre part par Cooke (1967), pour les plantes peu exigeantes.

En revanche, les valeurs seuils pour $I R=95 \%$ des méthodes Dyer et Joret-Hébert, respectivement 90 et $73 \mathrm{mg} \mathrm{P}_{2} \mathrm{O}_{5} \bullet \mathrm{h}^{-1}$, sont significativement plus faibles que celles généralement retenues pour interpréter les résultats d'analyse de terre (Plet, 1990). Cette situation quelque peu contradictoire n'est d'ailleurs pas spécifique à ces deux méthodes. Ce décalage entre les niveaux d'entretien habituellement employés dans l'interprétation des analyses de terre et ceux proposés par ce travail peut avoir deux origines.

Il existe d'une part des situations agropédologiques particulières pour lesquelles les méthodes Dyer ou Joret-Hébert extraient des phosphates non immédiatement assimilables par les plantes. Les 2 exemples suivants illustrent parfaitement ce type de situations : i) la présence de matière organique fraîche en quantité importante (cas des prairies récemment retournées) et ii) l'emploi, jadis fréquent, de phosphates naturels (Admont et al, 1986). Le résultat est que, dans de telles situations, une réponse culturale peut être observée malgré un niveau élevé du statut $P$ du sol. II traduit l'inaptitude de la méthode d'analyse à prévoir le comportement cultural et la seule démarche possible dans ce type de situations est non pas de chercher à accroître la valeur seuil mais d'analyser l'échantillon de sol par une méthode plus appropriée (Fardeau et al, 1988).

D'autre part, les méthodes utilisées pour l'établissement des normes de diagnostic du statut phosphaté et le choix du seuil de signification statistique sont une source de variation de l'élaboration du niveau d'entretien. En particulier, une des difficultés inhérentes à l'établissement de niveaux seuils réside dans la variabilité des réponses culturales observées pour un site donné en relation avec le choix de la culture et le régime de fertilisation. La prise en considération au niveau de cette étude du blé, culture réputée comme une des moins exigeantes pour le phosphore, conduit à obtenir des valeurs seuils plus faibles que si une autre culture connue pour être plus exigeante en phosphore, telle que la betterave ou la pomme de terre, avait été choi- 
sie. Ce choix explique donc pour partie le décalage existant entre les niveaux d'entretien déterminés dans cette étude et ceux habituellement retenus.

\section{Régime optimal de la fertilisation phosphatée du blé}

Les valeurs du statut $\mathrm{P}$ du sol correspondant à $I R=95 \%$ (tableau IV) permettent de proposer un raisonnement de la fertilisation phosphatée du blé basé sur l'obtention d'un rendement en grain non significativement différent de celui obtenu lorsque la nutrition phosphatée du blé est optimale. Ces niveaux correspondent à la définition du niveau "d'entretien» du statut $P$ du sol à partir duquel 3 situations peuvent être distinguées pour définir le régime optimal de fertilisation phosphatée de la culture du blé.

\section{Pour une valeur analytique voisine du niveau d'entretien}

La réserve de phosphore assimilable présente dans le sol suffit à assurer une alimentation optimale en phosphore à la culture du blé. Pour maintenir le statut $P$ du sol à ce niveau, il est néanmoins indispensable d'apporter du phosphore pour éviter une diminution de cette réserve suite aux exportations culturales. Les données analytiques plurianuelles disponibles pour certains de ces essais (Boniface et Trocmé, 1988 ) et des données plus anciennes (Boniface et al, 1975) indiquent qu'une restitution de phosphore, sous forme soluble-eau, sensiblement égale à celle exportée par les récoltes, permet de maintenir le statut $P$ du sol, si toutefois la matière organique n'est pas détruite en trop grande quantité par les pratiques de travail du sol (Gachon, 1988). Par conséquent, l'apport d'engrais sur blé implanté sur des terres dont le statut $P$ est situé au niveau d'entretien ne devrait pas excéder $50 \mathrm{~kg} \mathrm{P}_{2} \mathrm{O}_{5}{ }^{\circ h a^{-1}}$ pour une culture intensive de blé.

\section{Pour des niveaux du statut $P$ supérieurs au niveau d'entretien}

Dans ce cas, l'absence d'apport peut être envisagée. La durée de l'impasse est fonction de la différence entre la valeur analytique du statut $P$ de la parcelle à fertiliser et le niveau d'entretien.
Le nombre encore limité d'études de longue durée entreprises sur des sols dont la teneur est supérieure au niveau d'entretien ne permet pas de répondre avec précision à cette question. $\mathrm{Ce}$ pendant, sur la base des connaissances acquises, il est possible d'estimer un ordre de grandeur de cette durée. En raison du pouvoir tampon des sols vis-à-vis des ions phosphate, un excédent de fumure de $2600 \mathrm{~kg} \mathrm{P} \mathrm{O}_{5}{ }^{\bullet h a^{-1}}$ accroît en moyenne la teneur des sols en $\mathrm{P}$ Olsen de $100 \mathrm{mg} \mathrm{P}_{2} \mathrm{O}_{5}{ }^{\bullet \mathrm{kg}^{-1}}$ sol (Boniface et Trocmé, $1988 \mathrm{p}$ 303). En faisant l'hypothèse que le pouvoir tampon du sol n'est pas modifié en période de prélèvements en phosphore par les cultures ou d'apport d'engrais phosphatée, un prélèvement de $50 \mathrm{~kg} \mathrm{P}_{2} \mathrm{O}_{5}{ }^{\bullet h a^{-1}}$ se traduirait par une baisse de la teneur en P-Olsen de l'ordre de $(100 \times 50) / 2600$, soit environ $2 \mathrm{mg} \mathrm{P}_{2} \mathrm{O}_{5}{ }^{\circ} \mathrm{kg}^{-1}$ sol. Pour une teneur en P.Olsen de $80 \mathrm{mg}$ $\mathrm{P}_{2} \mathrm{O}_{5}{ }^{\circ}$ ha ${ }^{-1}$, valeur fréquemment rencontrée dans des parcelles de grande culture enrichies de longue date (Morel, 1990), la durée potentielle de l'impasse, si la culture était systématiquement le blé, pourrait être de $(80-28) / 2=25$ ans. II est bien évident que cette valeur est à manier avec la plus grande prudence puisqu'elle a été calculée à partir de deux valeurs moyennes (le pouvoir tampon vis-à-vis des ions phosphate et le niveau d'entretien des sols au regard de la méthode Olsen) qui masquent la disparité des situations agropédologiques. Néanmoins, pour des sols à pouvoir tampon modéré (ex : limon), à profondeur d'enracinement élevée et pour lesquels le statut organique est maintenu, la valeur de 25 ans indique que l'agriculteur peut envisager une réduction temporaire de la fertilisation $P$ sur les parcelles cultivées en blé et dont la teneur en $P$ extrait par la méthode Olsen est supérieure à 80 $\mathrm{mg} \mathrm{P}_{2} \mathrm{O}_{5} \bullet \mathrm{kg}^{-1}$.

\section{Pour des sols de grandes cultures dont les teneurs sont inférieures au niveau d'entretien}

Ces sols, très peu représentés sur le territoire français, nécessitent des apports de phosphore supérieurs aux quantités exportées par les récoltes pour atteindre le niveau d'entretien. Néanmoins, il est intéressant de noter sur la figure 5 que, pour des teneurs analytiques en P-Olsen inférieures au niveau d'entretien de $28 \mathrm{mg}$ $\mathrm{P}_{2} \mathrm{O}_{5}{ }^{\circ} \mathrm{kg}^{-1}$, une fumure annuelle égale à $\mathrm{P}_{1}$ permet d'obtenir dans 3 sites sur 4 un rendement non significativement différent du rendement mesuré en conditions optimales d'alimentation 


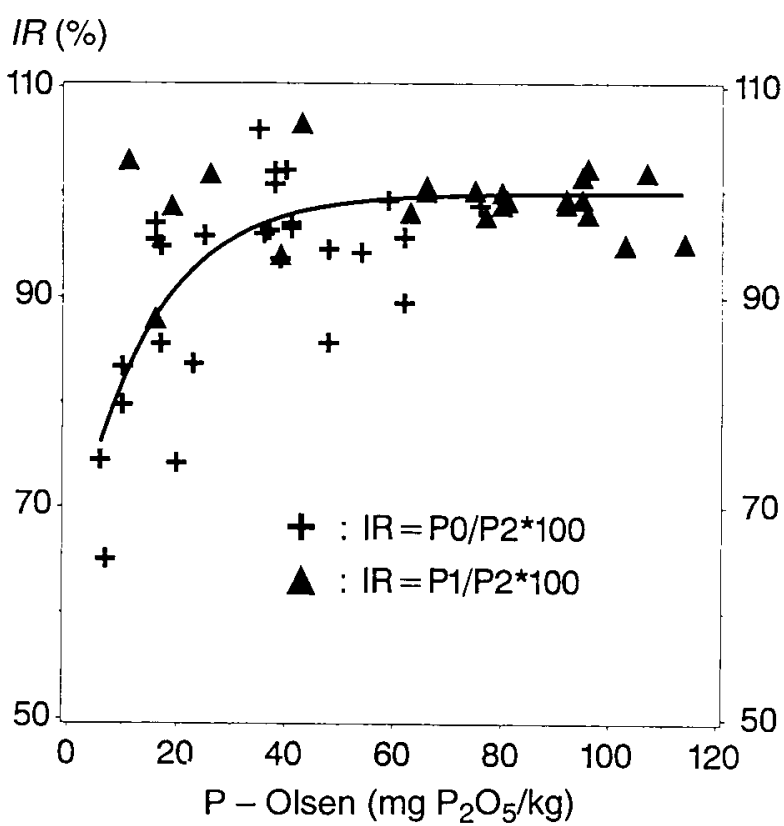

Fig 5. Influence du régime de fertilisation phosphatée sur l'indice de rendement du blé $(I R)$ en relation avec la quantité de phosphore du sol extrait par la méthode Olsen (P-Olsen).

phosphatée. Ce résultat confirme ceux obtenus lors de la comparaison des rendements culturaux obtenus à la suite d'une fertilisation récente à ceux obtenus à la suite d'une surfertilisation ancienne : sur céréale l'apport d'un engrais $P$ soluble-eau en quantité à peine supérieure à $P_{1}$ sur des parcelles appauvries de longue date permet d'obtenir en 2 ans, voire moins, un rendement non significativement différent de celui obtenu sur des parcelles antérieurement très enrichies (Delas, 1991). Ce résultat est en accord avec les données d'un travail précédemment publié (Sharpley, 1986), concluant qu'un apport de $70 \mathrm{~kg} \mathrm{P}_{2} \mathrm{O}_{5}{ }^{\bullet} \mathrm{ha}^{-1}$ suffisait pour obtenir un accroissement maximal du rendement en grain du blé sur un sol initialement peu pourvu en phosphore.

\section{CONCLUSION}

Une stratégie générale de la fertilisation phosphatée a été développée en France il y a 40 ans environ. Cette stratégie repose sur la détermination d'un niveau de réserves en phosphore assimilable dans le sol, appelé niveau d'entretien, et défini comme étant le niveau pour lequel les cultures les plus fréquentes de la rotation placées dans des conditions optimales de production ne réagissent pas à l'apport d'engrais phosphaté dans les conditions pédoclimatiques locales (Bo- niface, 1988). Malgré son intérêt, tant sur le plan économique (obtention d'un rendement optimal) que sur le plan agronomique (maintien du potentiel alimentaire du sol en phosphate), cette stratégie n'a pas réellement été mise en application dans la pratique agricole.

L'existence de références diverses sur le niveau d'entretien est probablement la cause essentielle de l'échec partiel de cette stratégie sur le terrain. L'impossibilité d'établir actuellement un référentiel fiable et accepté de tous, malgré les multiples tentatives entreprises, a pour origine le contenu trop général de la définition du niveau dit d'entretien. Cette définition ne fait référence à aucune culture en particulier. C'est pourquoi nous avons exploré la voie qui consistait à établir le niveau d'entretien du statut $P$ du sol non pour l'ensemble des plantes de grande culture mais pour une culture donnée : le blé.

L'analyse de 55 couples essais $x$ années de données analytiques et culturales permet de conclure que pour une culture intensive de blé, le niveau d'entretien du statut phosphaté du sol, exprimé en $\mathrm{mg}_{2} \mathrm{O}_{5}{ }^{\bullet} \mathrm{ha}^{-1}$, est situé aux alentours de 90 pour la méthode Dyer, 73 pour la méthode Joret-Hébert, 28 pour la méthode Olsen et 8,7 pour la valeur de $\mathrm{E}_{\mathrm{Pie} 1}$; et ce niveau peut être entretenu par une fertilisation annuelle voisine de $50 \mathrm{~kg} \mathrm{P}_{2} \mathrm{O}_{5} \bullet \mathrm{ha}^{-1}$.

Mais la méthodologie décrite dans ce travail et basée sur la seule prise en compte du statut phosphaté comme variable explicative du rendement relatif du blé permet d'expliquer environ $50 \%$ de la variabilité expérimentale. Trois voies de travail sont désormais nécessaires pour préciser l'influence de chacune des composantes des systèmes de culture (succession culturale; milieu sol-climat; techniques culturales) sur la valeur du niveau d'entretien du statut $P$ du sol.

II s'agit dans un premier temps d'établir les niveaux d'entretien pour l'ensemble des cultures présentes dans les rotations culturales des zones de grande culture, afin de raisonner la fertilisation phosphatée, non plus globablement, mais en considérant la rotation culturale du système de culture. Pour couvrir une large gamme de systèmes de culture, une attention particulière devrait être portée, d'une part à une plante telle que le maïs conduit en conditions irriguées, pour lequel les prélèvements totaux sont supérieurs à ceux du blé, et d'autre part aux plantes réputées exigeantes (ITCF, 1988) telles que la pomme de terre ou la betterave à sucre (Cooke, 1967; Trocmé et Boniface, 1972). 
Par ailleurs, il faut confirmer ou infirmer les niveaux d'entretien déterminés par ce travail dans des situations agropédologiques pour lesquelles existent de fortes contraintes sol-climat sur l'alimentation phosphatée du blé : terre caillouteuse et de faible profondeur, sol sableux.

Enfin, il s'agit d'étudier les relations existant entre le niveau d'intensification du système de culture et le niveau d'entretien qui lui est associé.

Cette stratégie de fertilisation devrait éviter les pratiques trop fréquentes de surfertilisation phosphatée dommageables à la fois pour le rendement économique de l'agriculteur et pour notre environnement.

\section{RÉFÉRENCES}

Admont PH, Boniface R, Fardeau JC, Jahiel M, Morel Ch (1986) Observations sur les mesures actuelles de dosage du phosphore assimilable des sols. Applications à l'étude de la valeur fertilisante des phosphates naturels. CR Acad Agric Fr 72, 1, 69-79

Azzaoui A, Hanson RG, Soltanpour PN (1989) Wheat requirements on calcareous Moroccan soils. I. A comparison of Olsen, Soltanpour and $\mathrm{CaCl}_{2}$ soil tests. Commun Soil Sci Plant Anal 20 (788), 869-891

Barrow NJ (1980) Evaluation and utilization of residual phosphorus in soils. In: The role of phosphorus in agriculture (FE Khasawneh, EC Sampl, EJ Kamprath, eds) Am Soc of Agron, Madison, 333-360

Boniface R, Fardeau JC, Trocmé S (1975) Observations sur les fumures phosphatées d'entretien. $C R$ Acad Agric Fr 173-183

Boniface R, Trocmé S (1988) Essais sur la fumure phosphatée. In: Phosphore et potassium dans les relations sol-plante : conséquences sur la fertilisation. INRA, 279-402

Castillon $P$ (1991) Les essais de longue durée sur la fertilisation phosphatée des cultures annuelles et des prairies. Convention 2214 A DPE/INRA, ITCF, Baziège

Cooke GW (1967) The control of soil fertility. Crosby Lockwood, London

Delas J (1991) La fertilisation phosphatée rationnelle: rapport final. Convention 2214 A DPE/INRA. INRAAgronomie, Villenave d'Ornon

Fardeau JC (1981) Cinétique de dilution isotopique et phosphore assimilable des sols. Thèse de doctorat d'État, Paris 6

Fardeau JC, Morel C, Boniface R (1988) Phosphore assimilable des sols. Quelle méthode choisir en analyse de routine. Agronomie 8, 577-584

Fardeau JC (1991) Essais permanents de Grignon et Nérac : compte rendu des analyses de sols et interprétation des résultats. Convention 2214 A DPE/ INRA. CEN Cadarache, DPVE, St-Paul-lez-Durance
Fardeau JC, Morel C, Boniface R (1991) Cinétique de transfert des ions phosphate du sol vers la solution de sol : paramètres caractéristiques. Agronomie 11, 787-797

Fox RL, Saunders WMH, Rajan SSS (1986) Phosphorus nutrition of pasture species: phosphorus requirement and root saturation values. Soil Sci Soc Am J 50, 142-148

Gachon L (1969) Les méthodes d'appréciation de la fertilité phosphorique des sols. BuH AFES, Sci Sol 4, 17-31

Gachon L (1988) Conclusions générales. In: Phosphore et potassium dans les relations sol-plante: conséquences sur la fertilisation. INRA, 557-566

ITCF (1988) Exemples d'élaboration de normes régionales. Spécial fertilisation phosphore et potasse. Perspect Agric 127, 142-164

Julien $\mathrm{JL}$ (1989) Détermination de normes d"interprétation d'analyse de terre en vue de la fertilisation potassique. L'exemple de la BasseNormandie. Sci Sol 27, 131-144

Martinez J, Delas J (1990) Les essais de longue durée INRA sur la fertilisation phosphatée : recueil et synthèse des données récentes. Convention d'étude 90/034 INRA-IMPHOS. INRA-agronomie, Villenave d'Ornon

Memon K, Fox RL (1983) Utility of phosphate sorption curves in estimating the phosphorus requirements of cereal crop wheat (Triticum aestivum). In: Proceedings of the 3rd international congress on phosphorus compounds. IMPHOS, Casablanca, 217-230

Morel C, Fardeau JC (1987) Le phosphore assimilable des sols intertropicaux : ses relations avec le phosphore extrait par deux méthodes chimiques. Agron Trop 42, 248-257

Morel C (1988) Analyse, par traçage isotopique, du comportement du phosphore dans les systèmes sol-engrais-plante : conséquences en matière de fertilisation. Thèse université d'Aix-Marseille, $169 p$

Morel C, Fardeau JC (1989) Native and fresh fertilizer phosphorus uptake as affected by rate of application and $P$ fertilizers. Plant Soil 115, 123-128

Morel C (1990) Statut phosphaté des sols du pays de Caux. In: Techniques betteravières. ITB-HauteNormandie, 27-31

Morel C, Plenchette C (1991) Conduite de la fertilisation phosphatée des sols fertilisés depuis des décennies: rapport des études complémentaires effectuées sur 4 essais INRA. Convention d'étude 2214 A DPE/INRA, INRA-Agronomie, BV 1540, Dijon

Nelson LA, Anderson RL (1980) Partitioning of soil test-crop response probability. Soil testing: correlating and interpreting the analytical results. $A S A$ Spec Publ 29

Plet P (1990) Analyse des sols cultivés. Tech Agric Fasc 1300, 1-17

Salcedo IH, Bertino F, Sampaio EVSB (1991) Reactivity of phosphorus in northeastern soils asses- 
sed by isotopic dilution. Soil Sci Soc Am J 55, 140-145

SAS Institute (1987) The NLIN procedure. In: SAS/ STAT guide for personal computers. SAS Institute Inc, Cary NC, $6^{e}$ édn, 675-712

Sharpley AN (1986) Disposition of fertilizer phosphorus applied to winter wheat. Soil Sci Soc Am J 50, 953-958
Tran ST, Fardeau JC, Giroux M (1988) Effects of soil properties on plant available phosphorus determined by the isotopic dilution phosphorus-32 method. Soil Sci Soc Am J 52, 1383-1390

Trocmé S, Boniface R (1972) Synergie des réserves du sol et des engrais récemment appliqués. Bull AFES 4-5, 161-174 